\title{
Reintroduction and restocking: guidelines for bird recovery programmes
}

\author{
JEFFREY M. BLACK
}

\begin{abstract}
Summary
Reintroduction and restocking programmes are conservation tools which may be employed when a wild population is otherwise beyond recovery. The decision to undertake such programmes should be based on a series of "feasibility" assessments (e.g. the bird's ecology, current threats, suitability of available stock and regional human socioeconomic implications). Releases should only take place when the habitat is capable of sustaining a viable population and the original constraining factors no longer operate. Releasing birds into near-saturated areas may be harmful and should be avoided. Local, national and international support for the programme should be secured. The birds should be of optimal quality in terms of behaviour, health and genetics and they should be reared, released and monitoring according to sound strategies and criteria. Assessment and adjustments of the programme should periodically be made after initial releases. Documentation of the programme should be circulated and/or published.
\end{abstract}

\section{Introduction}

The ideas for this paper were formulated during an international meeting of conservation managers and scientists organized by the International Council for Bird Preservation (ICBP) and the Wildfowl and Wetlands Trust (WWT). The subject of the meeting, held at Slimbridge in December 1988, was reintroductions and their value to conservation. During the meeting it was agreed that an approved set of guidelines was needed to ensure that all recovery efforts that involve releasing birds from captivity should enjoy successful outcomes, by ultimately reviving or retrieving populations that are critically threatened.

This paper contains those approved guidelines. In it are outlined how to initiate and conduct a recovery programme using the conservation tools of reintroduction and restocking. The original elements were assembled in a number of "brainstorming" sessions during the meeting. Creative contributions were made by several experts with a variety of conservation achievements (see Acknowledgements). In addition, a number of workers provided a fertile atmosphere by presenting overviews of their particular recovery programmes. Several documents provided us with considerable guidance. These are listed in the reference section.

\section{Principles and procedures}

Reintroduction is the considered release of (normally captive-bred) individuals of a species within their original range, with the aim of establishing a self-sustain- 
ing and viable population. Restocking is the release of (normally captive-bred) individuals of an existing population, usually with the aim of enhancing population viability. These guidelines may also be applicable to inter-island translocations of endangered birds. Other translocations of wild-caught animals are not considered here.

The overriding priority in conservation is to maintain existing natural ecosystems and biological processes. Reintroduction and restocking are useful tools only when a population has either been lost or reduced to critically low levels and no other more effective conservation measures are likely to restore that population to viability. Such programmes must be conducted as an integral component of the wider ecological and socio-economic efforts in ecosystem protection or restoration.

Releasing birds into existing populations of the same species is risky because of the possibility of introducing disease, disruptive genetic material and/or causing adverse social competition for resources. In other words, releasing birds into healthy sub-populations should be avoided even if the species is threatened elsewhere.

As not all threatened bird species and habitats are suitable for these programmes, the first need is to establish criteria that enable conservationists to assess whether their target species qualifies for treatment before too much investment is made. Such an assessment process has been called a Population Viability Analysis by the IUCN Captive Breeding Specialist Group. Prior to capturing birds or building a breeding facility, the first step is to conduct a feasibility study, which is here outlined in two phases.

If the species and the current status of its original environment fit the feasibility criteria, the recovery project can enter the planning and preparation phase, when budgets, staffing needs and a programme of events should be formalized. In many cases, a team of workers will need to be involved, including habitat managers, educators, aviculturists and field biologists. During our review of several case studies, e.g. the Peregrine Falcon Falco peregrinus and the Hawaiian Goose Branta sandvicensis, it became obvious that a long-term commitment of effort and finance was perhaps paramount among the various components that make a successful recovery programme.

Once the decision to proceed with a reintroduction or restocking programme has been made, several factors need to be considered about capture techniques, styles of housing, transport, rearing and release. Some species will need to be trained to avoid predators, while others should be reared with some degree of parental involvement. Other considerations include diet, health, the optimal size and composition of the group and the severity of the release experience. In some situations local communities as well as government officials will need to be convinced that the conservation of the species is essential in order to ensure their support for, and maintenance of, the necessary protective measures.

The actual release of birds takes the programme into a fourth phase, involving the constant monitoring of both the birds and the threats they may encounter. Despite the considerable expense already incurred, it is at this stage essential to initiate a long-term study of the progress being made in the wild, not only to protect the birds from avoidable losses but also to capitalize on initial investments. As the monitoring proceeds (usually with periodic further releases of 
birds), so a final phase must follow: assessment, adjustment and documentation of the techniques that have been employed during the early stages. Often recovery programmes go through long periods of reshaping until the fruits of success are realized.

For two reasons reintroduction and restocking programmes should be undertaken after mature consideration: first, such programmes require huge commitments in terms of finance and human effort; second, long-term habitat maintenance is essential. This second point is perhaps the more significant. Often a bird species nears extinction because its environment has been altered. In these cases, managers will have to reshape current ecosystems to enable the original species to re-establish itself by, for example, removing exotic predators or enhancing existing food supplies. Even in those cases where the habitat remains intact and the original cause of the species's decline has been removed or disappeared (as with DDT and birds of prey), the recovery team members should be prepared for a significant degree of involvement in conserving and/or enhancing the habitat under consideration.

\section{Phase 1: Feasibility study}

Prior to the capturing of birds for reintroduction and restocking purposes, investigations should be undertaken to satisfy a number of crucial aspects that will influence the feasibility of any such intervention.

(1) It is essential to determine, as far as possible, the demographic parameters of the remaining population and the species's ecological requirements.

(2) It is essential to assess the abiotic and biotic features in the species's ecosystem that have recently changed or that are likely to change in the foreseeable future, and how these may affect the livelihood of the species.

(3) An evaluation of the costs and benefits (both material and otherwise) of the recovery programme to any local human populations, and hence an assessment of their openness to cooperate, is necessary.

(4) The availability of suitable release stock needs careful assessment, with a precise determination of the number and taxonomic status of birds that could be used in the programme. The birds must be of the same taxon as that previously occurring in the area (as long as that taxon is extant). If purely captive stocks are to be used, they must be of the closest available subspecies or population to the original stock in terms of genetic, demographic and behavioural parameters.

\section{Phase 2: Conclusion of feasibility study}

Assuming that no further conservation efforts (habitat and species protection, etc.) can be initiated to revive the viability of the species, and assuming that the birds are of the sort that are amenable to a productive life in captivity, reintroduction and restocking programmes should still only be initiated if four further criteria are met.

(1) The original environment must be of adequate size and quality to support a viable population, or else has been restored and can be maintained at an adequate level. 
(2) The original causes of the species's decline must have been removed or are no longer effective.

(3) The original population in the chosen area must be extinct or small; releasing birds into a near-saturated area is not to be recommended since it may cause social disruption of the native population or introduce disease or deleterious genetic material.

(4) Potential disruption to human life-styles, property access and land utilization must be minimized according to a fully agreed and understood plan.

\section{Phase 3: Planning and preparation}

Once the decision has been taken to establish a captive population of the species for a reintroduction or restocking programme, and when appropriate funding is available, there are six general points of preparation and provision that need to be addressed before releases take place. Some investigations may need to be performed in controlled situations with surplus stock or with non-endangered species that are similar in behaviour and ecology (e.g. studying the Sandhill Crane Grus canadensis on behalf of the Whooping Crane G. americana).

(1) Where local human populations stand to be affected by the programme, community education campaigns and liaison are needed to ensure the broad understanding, acceptance and support of the inhabitants for the ongoing recovery efforts.

(2) Existing national and international regulations should be consulted and observed.

(3) The optimal rearing strategy, in terms of producing behaviourally and physically sound offspring, must be developed. Some birds will need to be taught the responses or skills necessary to survive in or utilize their wild environment; this may involve learning from parents, foster-parents or other creative techniques.

(4) An appropriate health screening of the birds and the potential release areas should be conducted. Where captive stocks are concerned, a sound health programme and genetic and studbook management programme should be initiated. Accidental introduction of new diseases or of disruptive genetic material must be avoided.

(5) The optimal release strategy, taking into consideration group composition, number, release patterns and techniques, timing and acclimatization, must be developed prior to actual releases into the wild.

(6) Achievement indicators (e.g. the rate of survival and recruitment over seasonal intervals, etc.) should be identified from which predictions of the programme duration can be made. The ultimate criterion for success is the establishment of a self-sustaining and viable population.

\section{Phase 4: Release and monitoring}

Once the habitat has been prepared and adequate numbers of birds are available (i.e. when there is a surplus to the long-term captive breeding programme), 
releases can be undertaken. Trained field biologists will be essential to conduct this phase of the programme.

(1) Based on previous investigations as required in phase 3 , point 5, the birds should be released at an appropriate age and in an appropriate group size and composition. An appropriate acclimatization period should be provided. All birds should be individually marked for subsequent identification, preferably without the need for recapture. Detailed records should be kept to enable revision of techniques and optimal success.

(2) Until the achievement indicators (phase 3, point 6) are all fulfilled, the following factors should be monitored: the ability of released birds to adapt to wild situations (especially in terms of feeding ecology, predator avoidance and integration with flock members), dispersal and habitat use, individual health, survival, recruitment, population structure and numbers, and causes of mortality.

(3) In addition to monitoring the birds themselves, a parallel monitoring of the key biotic and abiotic features in the ecosystem that may adversely affect the outcome of releases (see phase 1 , point 2 ) is likely to be essential.

\section{Phase 5: Assessment, adjustment and documentation}

Periodically, an assessment of the results of the monitoring studies in phase 4 should be undertaken and adjustment of all techniques should be considered or, if appropriate, the project should be discontinued. For example, if released birds are suffering from harassment from a previously unrecognized predator (e.g. eagles taking young releases), alternative sites should be chosen or escape skills taught prior to release.

In addition, the documentation and dissemination of the successes and failures should be expedited so as to solicit constructive suggestions and to allow similar programmes to benefit from the approaches taken and experience gained.

\section{Acknowledgements}

Contributors to these guidelines included Brian Bertram, Tom Cade, Nigel Collar, Christoph Imboden, Janet Kear, Georgina Mace, Peter Olney, Michael Ounsted, Myrfyn Owen, Mark Stanley Price, Mike Rands, Mike Scott, Ulie Seal, Richard Veitch and Hartmut Walter.

\section{Bibliography}

Barclay, J. H and Cade, T. J. (1983) Restoration of the peregrine falcon in the eastern United States. Bird Conservation 1: 3-37.

Black, J. M., Duvall, F., Hoshide, H., Medeiros, J., Natividad Hodges, C., Santos, N. and Telfer, T. (in press) The current status of the Hawaiian goose Branta sandvicensis and its recovery programme. Wildfowl 42.

Boitani, L. (1976) Proceedings of the seminar, Re-introductions: techniques and ethics. Pp.22-23 in U.K. Committee for International Nature Conservation, eds. Wildlife 
introductions to Great Britain: some policy implications for nature conservation (1979). Unpublished.

Cade, T. J., Enderson, J. H., Thelander, C. G. and Clayton, M. W. (1988) Peregrine falcon populations: their management and recovery. Boise, Idaho: The Peregrine Fund, Inc.

Gipps, J. H. W. (1991) Beyond captive breeding: re-introducing endangered mammals to the wild. Oxford: Clarendon Press.

IUCN (1987) The IUCN position statement on translocation of living organisms: introductions, re-introductions and re-stocking. Gland, Switzerland: International Union for Conservation of Nature and Natural Resources, unpublished.

Perrins, C. M., Lebreton, J.-D. and Hirons, G. J. M., eds. (1991) Bird population studies: relevance to conservation and management. Oxford: Oxford University Press.

Scott, J. M. and Carpenter, J. W. (1987) Release of captive-reared or translocated endangered birds: what do we need to know? Auk 104: 544-545.

Seal, U. S., Ballou, J. D. and Padua, C. V. (1990) Criteria for translocation/re-introduction of lion tamarin. In: Leontopithecus: population viability analysis. IUCN Captive Breeding Specialist Group, unpublished.

Soulé, M. E. (1987) Viable populations for conservation. New York: Cambridge University Press.

Soulé, M. E. and Wilcox, B. A. (1980) Conservation biology: an evolutionary-ecological approach. Sunderland, Mass.: Sinauer Associates.

Temple, S. A., ed. (1978) Endangered birds: management techniques for preserving threatened species. Madison, Wisconsin: University of Wisconsin Press.

JEFFREY M. BLACK

The Wildfowl and Wetlands Trust, Slimbridge, Gloucestershire GL2 $7 B T$, U.K. 